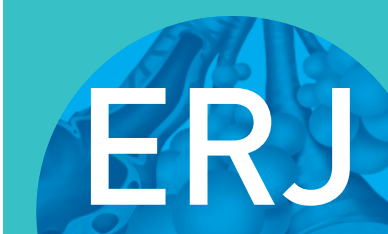

open research
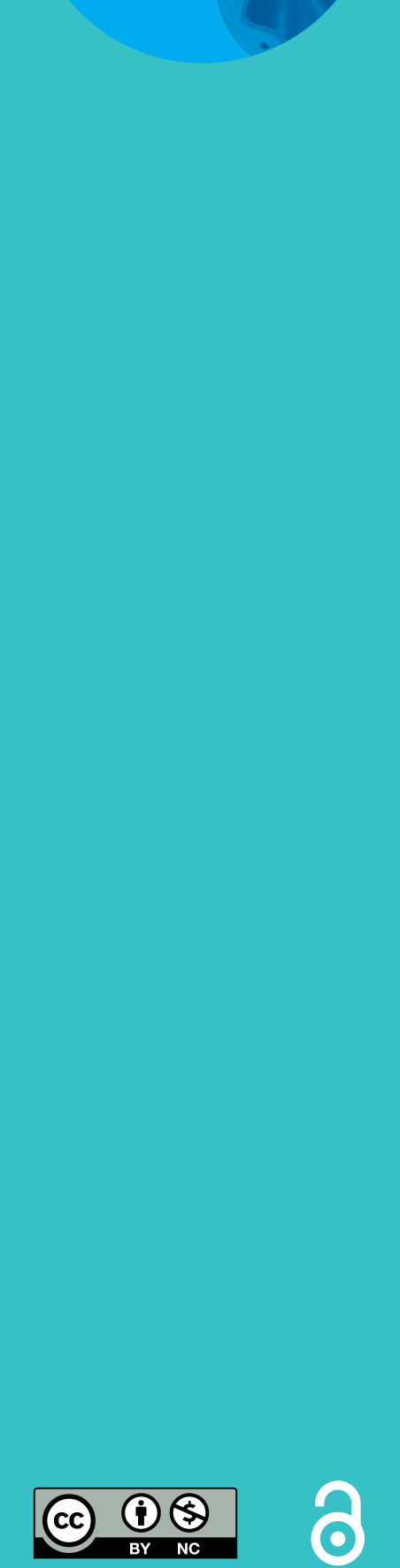

\section{Detailed characterisation of the tuberculosis epidemic in Western Sydney: a descriptive epidemiological study}

\author{
Sophie Norton ${ }^{1}$, Shopna K. Bag ${ }^{1,2}$, Jin-Gun Cho $\mathbb{1}^{2,3,4}$, Neil Heron ${ }^{3}$, \\ Hassan Assareh ${ }^{5}$, Laila Pavaresh ${ }^{1,4}$, Stephen Corbett ${ }^{1,2}$ and Ben J. Marais ${ }^{2,6}$
}

Affiliations: ${ }^{1}$ Western Sydney Local Health District, Public Health Unit, Parramatta, Australia. ${ }^{2}$ The University of Sydney, Camperdown, Australia. ${ }^{3}$ Parramatta Chest Clinic, Parramatta, Australia. ${ }^{4}$ Westmead Hospital, Wentworthville, Australia. ${ }^{5}$ Epidemiology and Health Analytic, Western Sydney Local Health District, Parramatta, Australia. ${ }^{6}$ The Children's Hospital at Westmead, Westmead, Australia.

Correspondence: Sophie Norton, Western Sydney Public Health Unit, Gungurra, Building 68, Cumberland Hospital Campus, Fleet Street, North Parramatta, New South Wales, Australia. E-mail: sophie.nortonahealth. nsw.gov.au

ABSTRACT Traditional tuberculosis (TB) epidemiology reports rarely provide a detailed analysis of TB incidence in particular geographic locations and among diverse population groups. Western Sydney Local Health District (WSLHD) has one of the highest TB incidence rates in Australia, and we explored whether more detailed epidemiological analysis could provide a better overview of the local disease dynamics.

Using multiple relevant data sources, we performed a retrospective descriptive study of TB cases diagnosed within the WSLHD from 2006 to 2015 with a specific focus on geographic hotspots and the population structure within these hotspots.

Over the study period nearly $90 \%$ of Western Sydney TB cases were born in a high TB incidence country. The TB disease burden was geographically concentrated in particular areas, with variable ethnic profiles in these different hotspots. The most common countries of birth were India (33.0\%), the Philippines (11.4\%) and China (8.8\%). Among the local government areas in Western Sydney, Auburn had the highest average TB incidence (29.4 per 100000) with exceptionally high population-specific TB incidence rates among people born in Nepal (average 223 per 100000 population), Afghanistan (average 154 per 100000 population) and India (average 143 per 100000 population).

Similar to other highly cosmopolitan cities around the world, the TB burden in Sydney showed strong geographic concentration. Detailed analysis of TB patient and population profiles in Western Sydney should guide better contextualised and culturally appropriate public health strategies.

@ERSpublications

High migration from tuberculosis (TB)-endemic settings to Western Sydney is driving overrepresentation among TB cases of specific cultural groups within geographic "hotspots", requiring contextualised and culturally appropriate public health strategies http://bit.ly/2LqusU9

Cite this article as: Norton S, Bag SK, Cho J-G, et al. Detailed characterisation of the tuberculosis epidemic in Western Sydney: a descriptive epidemiological study. ERJ Open Res 2019; 5: 00211-2018 [https://doi.org/10.1183/23120541.00211-2018].

This article has supplementary material available from openres.ersjournals.com

Received: 09 Nov 2018 | Accepted after revision: 18 June 2019

Copyright $\odot$ ERS 2019. This article is open access and distributed under the terms of the Creative Commons Attribution Non-Commercial Licence 4.0. 


\section{Introduction}

Despite relatively low numbers, tuberculosis (TB) continues to pose public health challenges in developed countries, mainly due to increased travel and migration [1]. Australia has maintained a low national TB incidence rate of $\sim 6.0$ cases per 100000 population since the 1990s [2], but progress towards TB elimination has stagnated, with wide variation between states and territories that mainly reflect differences in immigration patterns [2]. TB notification numbers are highest in New South Wales (NSW) and Victoria, accounting for approximately two-thirds of the national TB burden [2], given high rates of migration to these states from high TB incidence countries.

Within NSW, Western Sydney local health district (LHD) has the highest TB incidence rate, due to its large and culturally diverse migrant population. Projections are that Western Sydney will experience $>50 \%$ growth in its population over the next 20 years (2016-2036), with most new arrivals coming from high TB incidence countries [3]. Immigrants from these high TB incidence countries and their first-generation offspring have an increased likelihood of prior and future exposure to TB.

A better understanding of local population demographics and TB epidemiology is essential to guide culturally appropriate public health interventions and patient care, but traditional TB epidemiological reports only present aggregate case numbers without a detailed analysis of specific geographic hotspots. This study aimed to provide a detailed overview of the epidemiological characteristics and geographical topography of the TB epidemic in Western Sydney to inform strategic planning and better-targeted public health interventions.

\section{Methods}

We performed a descriptive epidemiological study using a retrospective registry-based cross-sectional survey of all cases diagnosed with TB in the Western Sydney LHD over a 10-year period (2006-2015). Countries with a high TB incidence were defined as those reporting $\geqslant 40$ cases per 100000 population per year (116 countries, as per the NSW government's list updated in October 2016) [4]. This is the "high TB incidence" definition used by the Australian Department of Immigration and Border Protection (now Home Affairs), as well as immigration services in the United States of America, the United Kingdom, New Zealand and Canada. We used the STROBE (Strengthening the Reporting of Observational Studies in Epidemiology) checklist version 4 for cross-sectional studies when writing our report [5]. The study was approved by Western Sydney LHD human research ethics committee (AU RED LNR/16/WMEAD/191).

\section{Study population and data sources}

A flowchart (supplementary figure S1) provides an overview of all the databases used and the data extracted from each. TB case notification data were extracted from the New South Wales Notifiable Conditions Information Management System (NCIMS) (www.health.nsw.gov.au/epidemiology/Pages/ notifiable-conditions.aspx). Population data, including mid-year population estimates by local government area using 2011 boundaries, were obtained from the Australian Bureau of Statistics via the Secure Analytics for Population Health Research and Intelligence system (SAPHaRI) (www.health.nsw.gov.au/ epidemiology/Pages/saphari.aspx), and country of birth populations via the Australian Bureau of Statistics TableBuilder [6]. Data regarding babies born to Western Sydney mothers were extracted from the SAPHaRI Perinatal Data Collection (www1.health.nsw.gov.au/pds/ActivePDSDocuments/PD2015_025.pdf). Travel data were extracted from the Department of Immigration and Border Protection overseas arrivals and departures pivot tables [7], which document the cross-border movement of Australian residents and overseas visitors.

Western Sydney settlement data were extracted from the Department of Social Services, Settlement and Multicultural Affairs Settlement Reporting Facility [8] collating data from the Department of Immigration and Border Protection visa processing system, Medicare Australia and the Adult Migrant English Program. Western Sydney local government area socioeconomic indexes for areas scores for the index of relative socioeconomic disadvantage (IRSD) were obtained from 2011 census of population and housing data, recording the relevant decile (10\% population bandwidth) [9].

\section{Data analysis}

Descriptive analyses of TB notification data were undertaken using demographic, clinical and risk-factor data fields. Cases were categorised by country and region of birth according to World Health Organization (WHO) TB incidence data and defined geographical regions. Within Western Sydney LHD the average number of TB case notifications over the study period (2006-2015) was used to calculate TB incidence rates by country of birth; the country of birth population denominator was obtained from 2011 census data. The residential addresses of $\mathrm{TB}$ cases were geocoded using GOPHER (geocoder optimised for 
population health and epidemiological research) on SAPHaRI and mapped as single case points, with aggregated local TB incidence rates calculated using $\mathrm{R}$ environment version 3.0.0 [10].

\section{Results}

During the 10-year study period, 1218 active TB cases were notified in Western Sydney LHD, with a TB incidence of 14.1 per 100000 population in 2006 and 12.4 per 100000 in 2015 (range over the study period 12.0-17.5 per 100000). The average TB incidence rate in Western Sydney LHD was 14.5 per 100000 population compared to the NSW average (excluding Western Sydney) of 5.6 per 100000 . Within Western Sydney LHD, TB incidence rates varied considerably between different local government areas, with the highest average rates recorded in Auburn (29.4 per 100 000) and Parramatta (21.6 per 100 000) (figure 1). The IRSD for Auburn was in decile two, with $56.8 \%$ of TB cases residing in a single postcode that fell in decile one (the most disadvantaged decile).

Table 1 summarises the changing demographic and clinical characteristics of TB cases notified in Western Sydney LHD over the study period. Most TB notifications occurred in young adults: $32.1 \%$ of notified TB cases were aged $25-34$ years and few $(n=54 ; 4.4 \%)$ were children (aged $<15$ years). The majority $(n=649$; $53.3 \%$ ) of cases had pulmonary TB; HIV co-infection was rare (1.1\% of those tested). However, HIV test results were unavailable for $26 \%$ of cases over the study period. Missing HIV test results were highest in 2006 ( $n=58 ; 54 \%$ of cases), improving over the 10 -year period to 2015 ( $n=20 ; 17 \%$ of cases).

Among TB cases in whom Australian residency status was recorded, 534 (65.2\%) out of 818 were permanent residents, 104 (12.7\%) overseas students and 47 (5.7\%) short-term visitors. Among immigrants and visitors with a required TB surveillance period (known as a TB undertaking (TBU)), 151 (13.4\%) out of 1125 were diagnosed with TB during this surveillance period; $112(10.0 \%)$ were previously under surveillance and $862(76.6 \%)$ had never been under surveillance. Of those who had never been under surveillance, 48 (5.6\%) were overseas students, $36(4.2 \%)$ were visitors and five $(0.6 \%)$ were on a refugee or humanitarian visa.

Figure 2 provides an overview of the countries and WHO regions of birth recorded. The most common countries of birth were India $(n=402 ; 33.0 \%)$; the Philippines $(n=139 ; 11.4 \%)$ and China $(n=107 ; 8.8 \%)$. Fewer than five $(<0.2 \%)$ cases were identified among Indigenous Australian (Aboriginal or Torres Strait Islander) people. The average annual TB case numbers and incidence rates in different local government

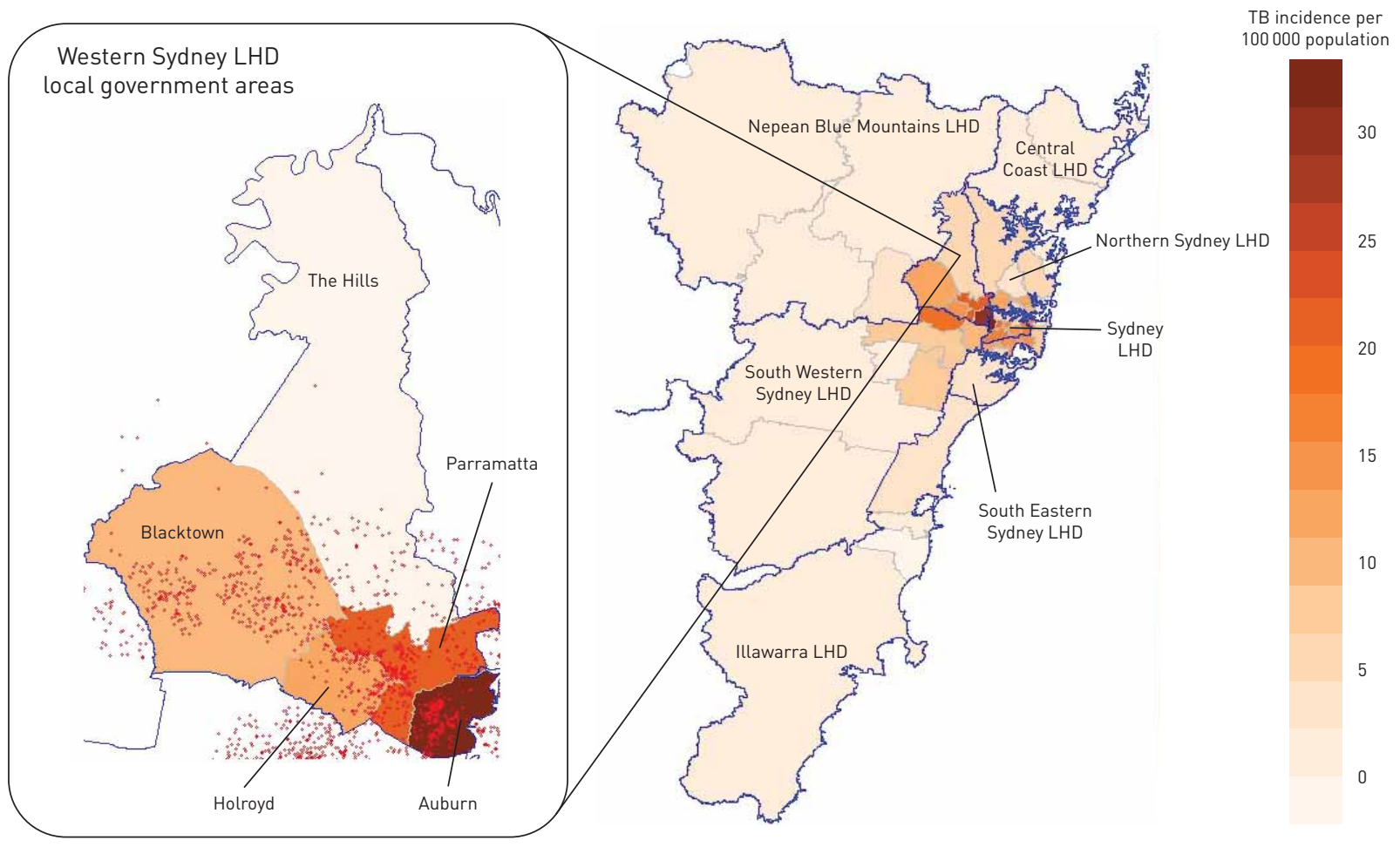

FIGURE 1 Heat map of average tuberculosis (TB) incidence rates in Metropolitan Sydney (2006-2015); with a focus on Western Sydney Local Health District (LHD). The legend reflects TB incidence per 100000 population. The enlarged panel demonstrates local government areas within Western Sydney LHD. Blue lines separate LHDs and red dots represent residential location of TB patients. 


\begin{tabular}{|c|c|c|c|c|}
\hline & \multicolumn{3}{|c|}{ Year } & \multirow{2}{*}{$\begin{array}{c}\text { Total } \\
\text { 2006-2015 }\end{array}$} \\
\hline & 2006 & 2011 & 2015 & \\
\hline \multicolumn{5}{|l|}{ Sex } \\
\hline Male & $59(55.1)$ & $68(53.1)$ & 60 (52.2) & $653(53.6)$ \\
\hline Female & $48(44.9)$ & $60(46.9)$ & 55 (47.8) & $565(46.4)$ \\
\hline \multicolumn{5}{|l|}{ Age group years } \\
\hline$<5$ & NP & NP & NP & $21(1.7)$ \\
\hline $5-14$ & NP & NP & NP & 33 (2.7) \\
\hline $15-24$ & 18 (16.8) & $16(12.5)$ & $9(7.8)$ & $176(14.5)$ \\
\hline $25-44$ & $28(26.2)$ & $74(57.8)$ & $52(45.2)$ & $572(47.0)$ \\
\hline $45-64$ & $31(29.0)$ & $23(18.0)$ & 29 (25.2) & $277(22.7)$ \\
\hline$\geqslant 65$ & 22 (20.5) & $11(8.6)$ & 22 (19.2) & $139(11.4)$ \\
\hline \multicolumn{5}{|l|}{ Country of birth } \\
\hline India & 25 (23.4) & 54 (42.2) & 40 (34.8) & $402(33.0)$ \\
\hline Philippines & $16(15.0)$ & $10(7.8)$ & $11(9.6)$ & $139(11.4)$ \\
\hline China & $9(8.4)$ & $12(9.4)$ & 13 (11.3) & 107 (8.8) \\
\hline Afghanistan & 7 (6.5) & 5 (3.9) & $\mathrm{NP}$ & $60(4.9)$ \\
\hline Nepal & 0 & $7(5.5)$ & $8(6.9)$ & 52 (4.3) \\
\hline Australia & $6(5.6)$ & $8(6.2)$ & NP & 72 (5.9) \\
\hline Other countries & $44(41.1)$ & $32(25.0)$ & $29(25.2)$ & 386 (31.7) \\
\hline \multicolumn{5}{|l|}{ Residency status } \\
\hline Permanent resident & 0 & 77 (60.2) & 59 (51.3) & 534 (43.9) \\
\hline Overseas student & 0 & $21(16.4)$ & $8(7.0)$ & 104 (8.5) \\
\hline Visitor & 0 & NP & 14 (12.2) & 47 (3.9) \\
\hline Refugee & 0 & 0 & $\mathrm{NP}$ & $9(0.7)$ \\
\hline Other ${ }^{\#}$ & 0 & $16(12.5)$ & $18(15.6)$ & $114(9.4)$ \\
\hline Unknown & 0 & NP & NP & $10(0.8)$ \\
\hline Not completed & 107 (100) & $8(6.3)$ & 15 (13.0) & $400(32.8)$ \\
\hline \multicolumn{5}{|l|}{ Active TB surveillance } \\
\hline Current TBU & 12 (11.2) & $21(16.4)$ & $11(9.6)$ & $151(12.4)$ \\
\hline Previous TBU & $14(13.1)$ & $10(7.8)$ & 14 (12.2) & $112(9.2)$ \\
\hline Never on TBU & $75(70.1)$ & $87(68.0)$ & 75 (65.2) & $862(70.8)$ \\
\hline Unknown & 0 & $2(1.6)$ & $2(1.7)$ & 18 (1.5) \\
\hline Not completed & $6(5.6)$ & $8(6.2)$ & 13 (11.3) & $75(6.1)$ \\
\hline \multicolumn{5}{|l|}{ Indigenous status } \\
\hline Aboriginal or Torres Strait Islander & 0 & 0 & 0 & NP \\
\hline \multicolumn{5}{|l|}{ Disease type } \\
\hline Pulmonary & 53 (49.5) & $53(41.4)$ & 62 (53.9) & $558(45.8)$ \\
\hline Pulmonary + extrapulmonary & $13(12.2)$ & $9(7.0)$ & $10(8.7)$ & $91(7.5)$ \\
\hline Extrapulmonary & 41 (38.3) & $66(51.6)$ & $43(37.4)$ & $569(46.7)$ \\
\hline \multicolumn{5}{|l|}{ HIV infection } \\
\hline Negative & 49 (45.8) & $100(78.1)$ & 94 (81.7) & $890(73.0)$ \\
\hline Positive & 0 & 0 & $\mathrm{NP}$ & $13(1.1)$ \\
\hline Unknown & $58(54.2)$ & 0 & $\mathrm{NP}$ & $118(9.7)$ \\
\hline Not completed & 0 & $28(21.9)$ & 18 (15.7) & $197(16.2)$ \\
\hline Total & 107 & 128 & 115 & 1218 \\
\hline \multicolumn{5}{|c|}{$\begin{array}{l}\text { Data are presented as } n(\%) \text { or } n \text {. TBU: TB undertaking; NP: not published (small cell counts of }<5 \text { have } \\
\text { been suppressed for privacy and confidentiality reasons. The small number and one other cell in the same } \\
\text { column has been suppressed to prevent back-calculation). \#: including unauthorised person }(n=4) \text {, work } \\
\text { visas ( } n=9) \text {, bridging visas ( } n=8) \text {, applying for permanent residency ( } n=1) \text {, temporary resident visa }(n=2) \text {, } \\
\text { Australian citizen ( }=16) \text {, dependant/partner visa ( }=8) \text {, supportive parent visa ( } n=1 \text { ), New Zealand citizen } \\
(n=1) \text {, "other" not completed }(n=64) ; ~ " \text { : active TB surveillance status at time of TB diagnosis. }\end{array}$} \\
\hline
\end{tabular}

areas within Western Sydney LHD are reflected in table 2, including rates among people born in the most common countries of origin. The average TB incidence rate among the Australia-born population was low (2 per 100000) and most cases occurred within immigrant families. Overall, TB incidence rates were highest among people born in India (94 per 100000 population). Of the five countries of birth mentioned in table 2 all, except Nepal had lower TB incidence rates among residents in Western Sydney compared to WHO TB incidence estimates for their home countries. WHO TB incidence estimates for 2015 were at 
a)

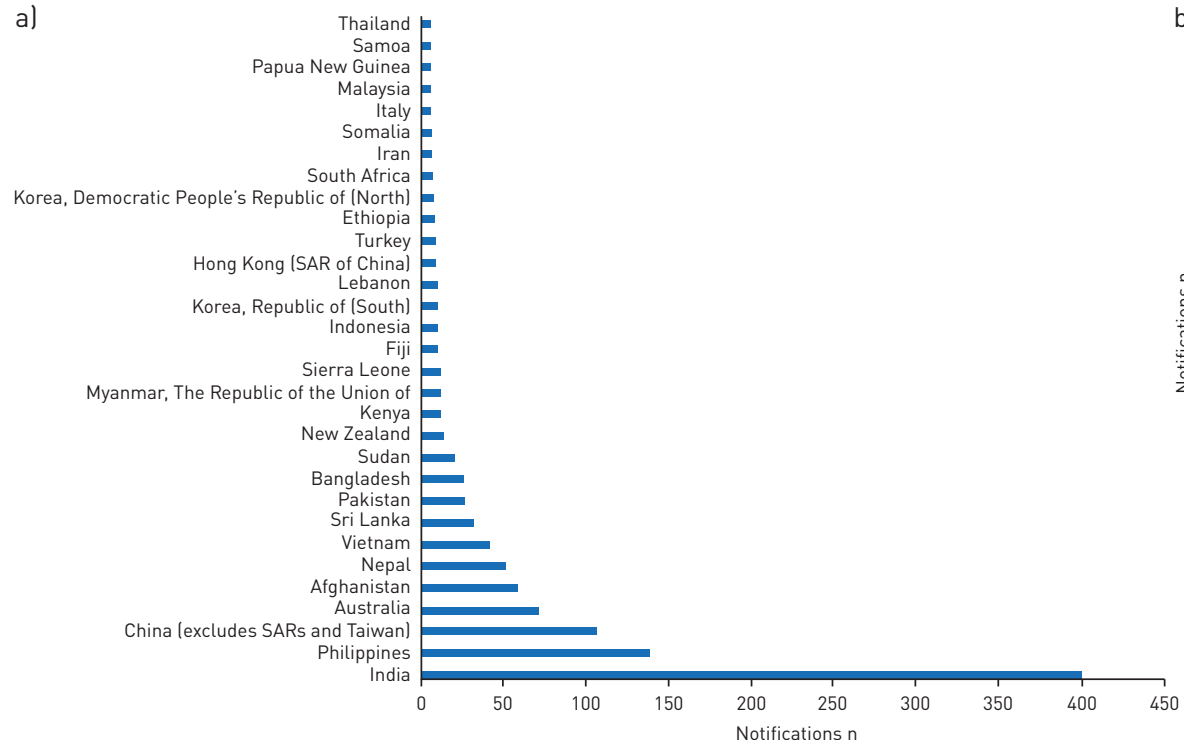

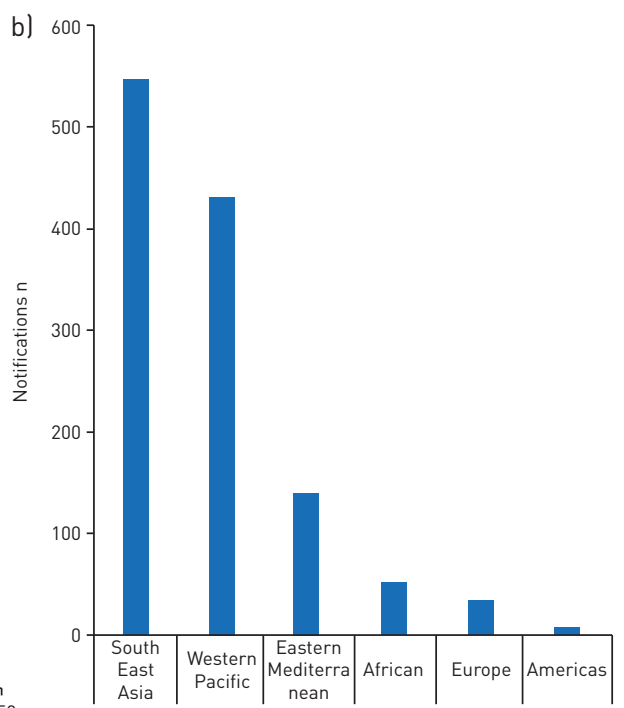

FIGURE 2 a) Country and b) World Health Organization (WHO) region of birth of tuberculosis (TB) cases notified in Western Sydney Local Health District from 2006 to 2015. SAR: special administrative region.

least twice as high in the relevant countries of origin, compared to rates in Western Sydney (India: 217 per 100000, 2.3 times higher; China: 67 per 100000, 2.0 times higher; the Philippines: 322 per 100000, 6.4 times higher; Afghanistan: 189 per 100000, 2.1 times higher), except for where rates in Western Sydney were twice as high as rates in Nepal (156 per 100000, 0.05 times lower) [11]. There were particular pockets of high TB incidence among the Nepal-born population in Auburn (223 per 100000), the Afghanistan-born population in Auburn (154 per 100000) and Holroyd (113 per 100000), and Philippines-born population in Parramatta (101 per 100000).

Figure 3 shows the number and percentage of TB cases born in high TB incidence countries. Overall, cases born in a high TB incidence country accounted for nearly $90 \%(1058 ; 87 \%)$ of all TB cases, with this proportion remaining stable over the 10 -year study period. The total number and percentage of people born in high TB incidence countries increased over this period, from 151153 ( $21 \%$ of the population) in 2006, to 207655 (26\% of the population) in 2011, to 292756 (31\% of the population) in 2016 [12]. People born in India increased the most: from 21980 (3.0\% of the population) in 2006, to 42968 (5.3\% of the population) in 2011, to 69807 (7.5\% of the population) in 2016 [12]. The percentage of Australia-born residents decreased from $56.4 \%$ (2006), to $54.4 \%$ (2011) to $50.2 \%$ (2016) [12].

The Department of Social Services recorded that 138999 immigrants settled within Western Sydney LHD from 2006 to 2015; $39827(28.7 \%)$ were born in India, 21643 (15.6\%) in China, 8418 (6.1\%) in The Philippines, 5988 (4.3\%) in Pakistan, 5172 (3.7\%) in Sri Lanka, 4446 (3.2\%) in Afghanistan and 4063

TABLE 2 Average annual tuberculosis (TB) case number and incidence rate in local government areas (LGAs) within Western Sydney Local Health District (2006-2015)

\begin{tabular}{|c|c|c|c|c|c|c|c|c|}
\hline & \multirow[t]{2}{*}{2011 LGA population ${ }^{\#}$} & \multicolumn{7}{|c|}{ Average annual TB case number and incidence rate ${ }^{\pi}$ (TB incidence per 100000 population) } \\
\hline & & Total & India & China & The Philippines & Afghanistan & Nepal & Australia \\
\hline Blacktown & 301097 & $37.8(13)$ & $10.4(69)$ & $1.3(42)$ & $9.2(48)$ & $0.7(41)$ & $0.9(188)$ & $3.4(2)$ \\
\hline Auburn & 73738 & $22.9(31)$ & $3.8(143)$ & $3.9(47)$ & $0.6(44)$ & 2.5 (154) & 3 (223) & 0.7 (3) \\
\hline Holroyd & 99163 & 14.5 (15) & $5.5(74)$ & 0.5 (18) & 0.5 (26) & 1.8 (113) & 0.1 (38) & $0.6(1)$ \\
\hline The Hills & 169872 & $9.3(5)$ & 2.5 (59) & 0.9 (15) & 0.9 (39) & 0.1 (27) & 0 & $1.1(1)$ \\
\hline
\end{tabular}

Data are presented as $\mathrm{n}$ or $\mathrm{n}(\%) .{ }^{\#}$ : 2011 national census data provided the population number used as denominator for TB incidence calculations; ": TB incidence rate calculations utilised the total number of people born in the country specified (as per 2011 census data) as the denominator; the five countries of birth from which the highest number of TB cases originated were included, with those born in Australia as comparator. 
(2.9\%) in Nepal. Babies delivered by mothers born in high TB incidence countries increased from 3723 ( $30 \%$ of all babies born) in 2006 to 6763 (46\% of all babies born) in 2015. Many young children (aged $<5$ years) travelled with their families to visit friends and relatives in TB-endemic areas, with the most common travel destinations being China, India and the Philippines. A large number of friends and relatives from TB-endemic countries visited immigrant families in Australia, but information regarding the TB disease burden in these short-term visitors is limited.

\section{Discussion}

Although Australia maintains a TB incidence of $<10$ per 100000 population, which is recognised by WHO as being in the pre-elimination phase, pockets of immigration-driven disease persist within large cosmopolitan cities. This is the reality in all countries with high rates of migration from TB-endemic settings, but it is rarely analysed in sufficient detail to guide tailored public health responses. In Western Sydney most TB cases were born in India, China or the Philippines. "country of birth specific TB case rates" are influenced by multiple factors, including the TB prevalence in migrants' home country, the prevalence within their particular "home community" and the size and vulnerability of the migrant population, the time since migration [13], as well as the frequency of travel to and from their home country [14].

Premigration screening for active TB $[2,15]$ as well better living standards and reduced TB exposure in Australia, probably explain the lower TB incidence seen in Western Sydney among migrants compared to their home country. However, this does not hold true for people born in Nepal. TB case detection is suboptimal and notifications are generally under-reported in Nepal [16], but WHO TB incidence estimates aim to correct for these factors [11]. Apart from underestimation at the national level, regional differences in TB incidence within Nepal and the regions from which the Western Sydney Nepalese population have immigrated, as well as sex balance [17] may also influence the observed rates. An additional consideration is the possibility that certain protective elements of living at altitude in Nepal, which is a more hypoxic environment and has been shown to enhance antimicrobial cellular immunity [18], may be lost in Australian migrants who live at sea level. In addition, many Nepalese TB patients are international students, and the high cost of living in Sydney may lead to stress and financial hardship that could increase TB vulnerability.

The geographical topography of TB patients in Western Sydney identified hotspots in areas with the highest socioeconomic disadvantage, similar to findings in London, where a prominent east-west gradient in TB incidence has been associated with areas of migrant settlement and socioeconomic disadvantage [19, 20]. Poverty is recognised as a major global driver of the TB epidemic and even in high-income countries low socioeconomic status remains a major TB risk factor [21, 22]. Poverty is associated with both increased TB exposure risk and increased risk of disease progression following TB infection [23]. Unlike the experience in other jurisdictions [2] and parts of NSW [24], Aboriginal and Torres Strait Islander populations were not over-represented among TB cases in Western Sydney.

Very high TB incidence rates, >100 per 100000 population, were noted among the Nepal-, Afghanistanand India-born populations in Auburn, the Afghanistan-born population in Holroyd and the Philippinesand India-born populations in Parramatta. Providing better contextualised public health interventions in these at-risk communities should be a priority. Immigrants with language and cultural backgrounds that differ from their recipient country are more likely to experience problems with healthcare access and health communication [25]. TB-associated stigma is also pronounced in certain cultures [26]. Studies in migrant populations in Melbourne and Canada indicated TB knowledge gaps, TB-associated stigma and limited healthcare access in particular groups, all of which impacted negatively on TB diagnosis and treatment $[27,28]$. A Sydney study identified communication problems when doctors discussed treatment of latent TB infection (LTBI) with migrants from culturally and linguistically diverse backgrounds, even with the use of interpreters [29].

Therefore, considering the best and most culturally appropriate methods to engage with at-risk communities require careful consideration, especially if targeted community screening and LTBI treatment is considered as a potential preventive strategy [30, 31]. Such a strategy should include the use of well-informed bilingual community health workers to increase awareness and knowledge about TB and the available services by using their cultural links within the respective migrant communities [32]. Similarly, the use of bilingual TB healthcare professionals within local TB services would assist to bridge the cultural gap between various ethnic communities and the healthcare system. The benefits and risks of community-based LTBI screening and treatment deserves formal evaluation, considering acceptability, potential stigmatisation and the high mobility of immigrant populations that might expose them to re-infection. High-risk groups in whom LTBI treatment may be most feasible include international students and healthcare workers. 


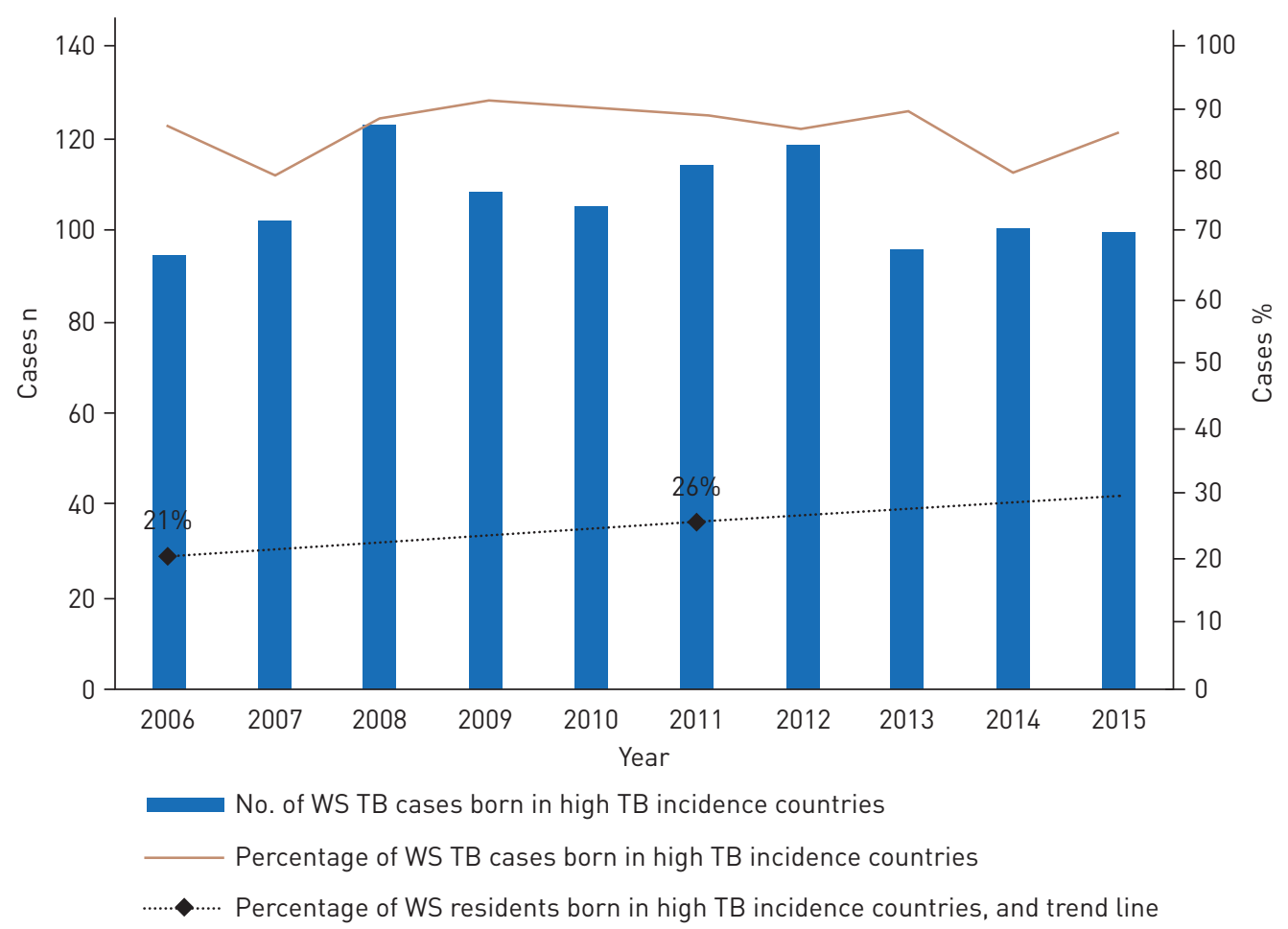

FIGURE 3 Number and percentage of tuberculosis (TB) cases notified in Western Sydney (WS) Local Health District who were born in a high TB incidence country (defined as TB incidence of $\geqslant 40$ per 100000 population). Census data from 2006 and 2011 were used to construct the trend line.

Population projections suggest a large increase in the Western Sydney population over the next 20 years [3], with most new arrivals coming from high TB incidence countries. This indicates the importance of supporting efforts to improve regional and global TB control. Given likely ongoing TB importation, the most important outcome from a public health perspective is to prevent local TB transmission, which can now be tracked as a key programme performance indicator. NSW were among the first jurisdictions in the world to implement routine whole-genome sequencing of all culture-confirmed TB cases (since October 2016), assisting rapid identification of drug resistant strains, tracking of local transmission dynamics and guiding targeted public health responses. Initial findings demonstrate limited local transmission [33, 34], but a commitment to "zero TB transmission" in line with the global TB elimination agenda in low-incidence settings [35], requires ongoing vigilance and enhanced national coordination.

Current offshore premigration screening aims to identify people with active $\mathrm{TB}$ who may pose a transmission risk to Australian citizens. It detects around 400-500 TB cases among long-term visa applicants every year [2], who are required to demonstrate treatment completion and clinical cure before a visa is granted. However, little consideration is given to the risk of future disease development among those who stay in Australia for a prolonged period of time, apart from linking those with suspicious chest radiographs to onshore surveillance systems $[15,36]$. A Canadian study found that $79 \%$ of migrants who developed TB were not identified to be at risk during initial radiographic screening [37]. These cases generally presented with more advanced disease and were associated with more secondary TB cases (local transmission) compared to those identified to be at risk and placed on post-migration surveillance [37]. Similarly, 77\% of foreign-born TB cases in Western Sydney were never placed on a TBU, with a further $10 \%$ developing TB after the period of surveillance. However, a recent NSW study showed that targeted post-migration surveillance was partially effective; detecting $63 \%$ of TB cases during follow-up [38]. These data indicate potential benefit from targeted LTBI screening and treatment, as well as active surveillance of high-risk cases. Given low but stagnant TB incidence rates in NSW over the past 20 years [39], it is clear that more proactive strategies are required for TB elimination.

Despite general consensus that LTBI treatment is a valuable tool [40], implementation remains limited in the absence of detailed cost-benefit analyses [30, 31]. A UK modelling study found that a single interferon- $\gamma$ release assay, combined with LTBI treatment, offered good value for money in immigrants from countries with a TB incidence $>150$ per 100000 population [41]. These findings influenced the current National Institute for Health and Care Excellence (NICE) guidelines [42], which acknowledge the 
need for population-tailored approaches that are context specific. A complicating factor that is rarely considered in modelling studies is the increased mobility and home country contact that immigrant families have in a modern globalised world, as suggested by the cross-border travel data that we assessed. This implies a risk of re-infection that may reduce the protective effect of LTBI treatment.

The TB re-infection risk is difficult to quantify in the absence of a reliable test, but children of immigrant families with recent travel to a high TB incidence country were found to be five times more likely to have a positive tuberculin skin test (TST) than those without travel [43], which provides an estimate of infection/re-infection risk. Among Australians with travel-related infections, a large proportion (81\%) of cases reported recent travel to their country of birth. Travel to visit friends and relatives posed an increased "all infection" risk, due to longer travel duration and increased likelihood of disease exposure [44]. Immigrant families in Western Sydney regularly travel to high TB incidence countries to visit friends and relatives, which place young children at risk of TB exposure, infection and disease, especially if they are not Bacille Calmette-Guérin (BCG) vaccinated [45]. Ideally, BCG vaccination should be offered at birth to immigrant families or be readily available as a travel vaccine in these vulnerable young children $[45,46]$.

Study limitations include the fact that we used routine notification data to identify TB cases and HIV test results were not recorded for a large proportion. However, NSW TB programme data are otherwise comprehensive and provide an unbiased overview of the total TB disease burden, while HIV testing rates have improved. In addition, we used a variety of complementary data sources to characterise the TB epidemic and local population dynamics in as much detail as possible. The contribution of TB importation is likely to be underestimated if we only consider non-Australian born cases, given that many Australia-born cases have parents from high $\mathrm{TB}$ incidence countries and/or have travelled to these countries for extended periods of time. Ethnicity of Australian-born cases could not be established, since this is not captured within the NCIMS database. The accuracy of future projections is highly dependent on government policy, but helps to plan for likely future scenarios and highlights the need for comprehensive data collection and dynamic strategies that are responsive to changing migration patterns.

\section{Conclusion}

Although Australia has an overall low burden of TB, we have demonstrated that the population in Western Sydney is highly cosmopolitan, with geographically confined foci of high $\mathrm{TB}$ incidence in particular immigrant populations. Current TB control policies focus on preventing cases with active TB from entering Australia and active post-migration screening of high-risk individuals, while LTBI screening and treatment is underutilised. Culturally sensitive LTBI treatment and active case-finding policies that incorporate fine grained assessment of epidemiological data and involve local communities should assist TB control and elimination efforts.

Acknowledgements: We thank the staff involved in the management of tuberculosis cases at Parramatta Chest Clinic (Parramatta, Australia) for providing notification data to the Notifiable Conditions Information Management System.

Author contributions: S. Norton, N. Heron, S.K. Bag, L. Pavaresh and J-G. Cho drafted the proposal with input from all authors. S. Norton investigated relevant data sources with input from S.K. Bag and N. Heron. S. Norton obtained data and carried out data analysis. H. Assareh produced the LGA map with data input provided by S. Norton. S. Norton drafted the initial manuscript under the guidance of B.J. Marais with input from J-G. Cho and S.K. Bag. All authors helped to refine the manuscript and approved the final version.

Conflict of interest: None declared.

\section{References}

1 World Health Organization (WHO). Towards TB Elimination: An Action Framework for Low-Incidence Countries. 2014. Geneva, WHO Press.

2 Toms C, Stapledon R, Coulter C, et al. Tuberculosis notifications in Australia, 2014. Commun Dis Intell Q Rep 2017; 41: E247-E263.

3 NSW Government, Planning and Environment. Population Projections, 2016 NSW population and household projections. www.planning.nsw.gov.au/Research-and-Demography/Demography/Population-projections Date last accessed: January, 2018. Date last updated: December 11, 2017.

4 List of Countries with a Tuberculosis Incidence of 40 cases per 100,000 Persons or Greater. NSW Government, NSW Health, 2016. www.health.nsw.gov.au/Infectious/tuberculosis/pages/high-incidence-countries.aspx Date last accessed: October 23, 2017. Date last updated: July 23, 2018.

5 von Elm E, Altman DG, Egger M, et al. The Strengthening the Reporting of Observational Studies in Epidemiology (STROBE) statement: guidelines for reporting observational studies. J Clin Epidemiol 2008; 61: 344-349.

6 Australian Bureau of Statistics. Census of Population and Housing, 2006 \& 2011 Census TableBuilder: Australian Bureau of Statistics. www.abs.gov.au/websitedbs/censushome.nsf/home/tablebuilder Date last accessed: May, 2017.

7 Australian Government, Department of Immigration and Border Protection. Overseas Arrivals and Departures Pivot Tables. https://data.gov.au/dataset/overseas-arrivals-and-departures Date last accessed: October 5, 2016. 
8 Australian Government, Department of Social Services, Settlement and Multicultural Affairs. Settlement Reporting Facility. www.dss.gov.au/our-responsibilities/settlement-and-multicultural-affairs/programs-policy/settlement-services/ settlement-reporting-facility Date last accessed: December 25, 2016.

9 Australian Bureau of Statistics. Census of Population and Housing: Socio-Economic Indexes for Areas (SEIFA), Australia, 2011 - Catalogue number 2033.0.55.001. 2011.www.abs.gov.au/ausstats/abs@.nsf/Lookup/2033.0.55. 001main+features100052011. Date last accessed: January, 2018

10 R: A language and environment for statistical computing. Vienna, R Core Team, R Foundation for Statistical Computing, 2016. www.r-project.org/

11 World Health Organization (WHO). Global Tuberculosis Report 2016. Geneva, WHO, 2016.

12 Australian Bureau of Statistics. Census of Population and Housing, 2016 Census Tablebuilder. Date last accessed: January 2018. www.abs.gov.au/websitedbs/censushome.nsf/home/tablebuilder.

13 Marks GB, Bai JUN, Simpson SE, et al. Incidence of tuberculosis among a cohort of tuberculin-positive refugees in Australia: reappraising the estimates of risk. Am I Respir Crit Care Med 2000; 162: 1851-1854.

14 Dobler CC, Fox GJ, Douglas P, et al. Screening for tuberculosis in migrants and visitors from high incidence settings: present and future perspectives. Eur Respir J 2018; 52: 1800591.

15 Australian Government, Department of Immigration and Border Protection. Health Examinations. www. homeaffairs.gov.au/trav/visa/heal/meeting-the-health-requirement/health-examinations Date last accessed: September, 2017.

16 National Tuberculosis Program Nepal, Annual Report 2073/74 (2017). Kathmandu, Government of Nepal Ministry Of Health, Department of Health Services, National Tuberculosis Center, 2017.

17 Kakchapati S, Choonpradub C, Lim A. Spatial and temporal variations in tuberculosis incidence, Nepal. Southeast Asian J Trop Med Public Health 2014; 45: 95-102.

18 Eisen S, Pealing L, Aldridge RW, et al. Effects of ascent to high altitude on human antimycobacterial immunity. PLoS One 2013; 8: e74220.

19 Hayward S, Harding R, McShane H, et al. Factors influencing the higher incidence of tuberculosis among migrants and ethnic minorities in the UK. F1000Res 2018; 7: 461.

20 London Assembly Health Committee Report: Tackling TB in London. London, UK, Greater London Authority, 2015.

21 Lönnroth K, Jaramillo E, Williams BG, et al. Drivers of tuberculosis epidemics: the role of risk factors and social determinants. Soc Sci Med 2009; 68: 2240-2246.

22 Marais BJ, Hesseling AC, Cotton MF. Poverty and tuberculosis: is it truly a simple inverse linear correlation? Eur Respir J 2009; 33: 943-944.

23 Marais BJ, Obihara CC, Warren RM, et al. The burden of childhood tuberculosis: a public health perspective. Int $J$ Tuberc Lung Dis 2005; 9: 1305-1313.

24 Outhred AC, Holmes N, Sadsad R, et al. Identifying likely transmission pathways within a 10-year community outbreak of tuberculosis by high-depth whole genome sequencing. PLoS One 2016; 11: e0150550.

25 Komaric N, Bedford S, van Driel ML. Two sides of the coin: patient and provider perceptions of health care delivery to patients from culturally and linguistically diverse backgrounds. BMC Health Serv Res 2012; 12: 322.

26 Craig GM, Daftary A, Engel N, et al. Tuberculosis stigma as a social determinant of health: a systematic mapping review of research in low incidence countries. Int J Infect Dis 2017; 56: 90-100.

27 Butcher K, Biggs B-A, Leder K, et al. Understanding of latent tuberculosis, its treatment and treatment side effects in immigrant and refugee patients. BMC Res Notes 2013; 6: 342.

28 Gao J, Berry NS, Taylor D, et al. Knowledge and perceptions of latent tuberculosis infection among Chinese immigrants in a Canadian urban centre. Int J Family Med 2015; 2015: 546042.

29 Dobler CC, Bosnic-Anticevich S, Armour CL. Physicians' perspectives on communication and decision making in clinical encounters for treatment of latent tuberculosis infection. ERJ Open Res 2018; 4: 00146-2017.

30 Fox GJ, Dobler CC, Marais BJ, et al. Preventive therapy for latent tuberculosis infection - the promise and the challenges. Int J Infect Dis 2017; 56: 68-76.

31 Byrne AL, Fox GJ, Marais BJ. Better than a pound of cure: preventing the development of multidrug-resistant tuberculosis. Future Microbiol 2018; 13: 577-588

32 Henderson S, Kendall E, See L. The effectiveness of culturally appropriate interventions to manage or prevent chronic disease in culturally and linguistically diverse communities: a systematic literature review. Health Soc Care Community 2011; 19: 225-249.

33 Gurjav U, Jelfs P, Hill-Cawthorne GA, et al. Genotype heterogeneity of Mycobacterium tuberculosis within geospatial hotspots suggests foci of imported infection in Sydney, Australia. Infect Genet Evol 2015; 40: 346-351.

34 Gurjav U, Outhred AC, Jelfs $\mathrm{P}$, et al. Whole genome sequencing demonstrates limited transmission within identified Mycobacterium tuberculosis clusters in New South Wales, Australia. PLoS One 2016; 11: e0163612.

35 Marais BJ, Walker TM, Cirillo DM, et al. Aiming for zero tuberculosis transmission in low-burden countries. Lancet Respir Med 2017; 5: 846-848.

36 Australian Government, Department of Immigration and Border Protection. Health Undertakings. https://archive homeaffairs.gov.au/trav/visa/heal/meeting-the-health-requirement/health-undertakings Date last accessed: April, 2019.

37 Asadi L, Heffernan C, Menzies D, et al. Effectiveness of Canada's tuberculosis surveillance strategy in identifying immigrants at risk of developing and transmitting tuberculosis: a population-based retrospective cohort study. Lancet Public Health 2017; 2: e450-e457.

38 Kaushik N, Lowbridge C, Scandurra G, et al. Post-migration follow-up programme for migrants at increased risk of developing tuberculosis: a cohort study. ERJ Open Res 2018; 4: 00008-2018

39 NSW Tuberculosis Program CDB. Tuberculosis in New South Wales Surveillance Report 2017. Sydney, Health Protection NSW, 2019.

40 Rangaka MX, Cavalcante SC, Marais BJ, et al. Controlling the seedbeds of tuberculosis: diagnosis and treatment of tuberculosis infection. Lancet 2015; 386: 2344-2353.

41 Pareek M, Bond M, Shorey J, et al. Community-based evaluation of immigrant tuberculosis screening using interferon $\gamma$ release assays and tuberculin skin testing: observational study and economic analysis. Thorax 2013; 68: 230-239.

42 National Institute for Health and Care Excellence. Tuberculosis, NICE Guideline. United Kingdom, 2016. Report No.: NG33. January 13, 2016. 
43 Lobato MN, Hopewell PC. Mycobacterium tuberculosis infection after travel to or contact with visitors from countries with a high prevalence of tuberculosis. Am J Respir Crit Care Med 1998; 158: 1871-1875.

44 Heywood AE, Zwar N, Forssman B, et al. The contribution of travellers visiting friends and relatives to notified infectious diseases in Australia: state-based enhanced surveillance. Epidemiol Infect 2016; 144: 3554-3563.

45 Marais BJ, Seddon JA, Detjen AK, et al. Interrupted BCG vaccination is a major threat to global child health. Lancet Respir Med 2016; 4: 251-253.

46 Gwee A, Rodrigo R, Casalaz D, et al. Infants born in Australia to mothers from countries with a high prevalence of tuberculosis: to BCG or not to BCG? Med J Aust 2013; 199: 324-326. 